\title{
Introdução - Arte e cultura material africana no Brasil: um campo em construção
}

Juliana Ribeiro da Silva Bevilacqua ${ }^{1}$

Quando recebi o convite para organizar um dossiê dos Anais do Museu Paulista que tivesse como foco a cultura material da África, deparei-me com o grande desafio de encontrar estudiosos no Brasil que pudessem colaborar com esta edição. Se os nossos laços históricos com o continente africano propiciaram o estudo de temáticas abordadas por diversas áreas do conhecimento - como é o caso daqueles relativos à escravidão e mais recentemente os voltados para a história da África, que têm apresentando notáveis avanços no país - o mesmo não se pode dizer dos estudos que focalizam especificamente a cultura material africana, seja no domínio da arqueologia, da história social ou da história da arte.

Trata-se, sem dúvida, de um campo em construção, em que as iniciativas e ações para o seu fortalecimento são ainda bastante tímidas. Não é fácil compreender os motivos para toda essa falta de atenção, ainda mais se lembrarmos que o primeiro artigo que se tem notícia dedicado ao tema no Brasil data de 1904 - "As Bellas Artes nos colonos pretos do Brazil" - escrito pelo médico maranhense Nina Rodrigues, que abordou pioneiramente um conjunto de peças afro-brasileiras e africanas.

Se, por outro lado, pensarmos na existência e formação das coleções africanas no Brasil, é possível afirmar que sua presença também não pode explicar esse quadro deficiente. A coleção africana do Museu Nacional, no Rio de Janeiro, tem, por exemplo, peças que entraram para o acervo desde o início do século XIX e, em meados do século XX, ela estava amplamente formada. Já a coleção africana
1. Historiadora, mestra e doutora em História social pela Universidade de São Paulo. Atualmente é pesquisadora no Museu de Arte de São Paulo (MASP). <jurisil@ gmail.com> 
do Museu paraense Emilio Goeldi, que foi constituída por peças coletadas na África central entre 1887 e 1904, passou a fazer parte do acervo do Museu desde a década de 1930.

Em 1958, Pietro Maria Bardi, em correspondência trocada com o galerista húngaro Ladislas Segy, tornou evidente o desejo de formar uma coleção africana para o Museu de Arte de São Paulo (MASP). Apenas um ano depois, Agostinho da Silva, uma das figuras fundamentais na criação do Centro de Estudos Afro-Orientais, em Salvador, também manifestou o interesse em formar uma coleção arricana desde a exposição "A Arte de um povo de Angola", realizada, em 1959, na Universidade da Bahia, com peças do Museu do Dundo.

Em 1969, Ulpiano Bezerra de Meneses, então diretor do Museu de Arqueologia e Etnologia da USP, colocou em prática o projeto de formar uma coleção africana para o MAE. Antes disso, o Museu Nacional de Belas Artes, no Rio de Janeiro, havia adquirido um conjunto de peças africanas que pertenceu ao diplomata Gasparino da Mata e Silva.

Desde então, outras iniciativas voltadas para formar coleções africanas no Brasil foram encabeçadas por figuras como Pierre Verger, que se mostrou fundamental na formação, entre outros museus, da coleção do Museu Afro-Brasileiro da Universidade Federal da Bahia, inaugurado em 1982. Mais recentemente, Emanoel Araujo foi determinante na constituição da coleção africana do Museu Afro Brasil, em São Paulo, instituição aberta em 2004.

Ainda que não seja voltado para o estudo dessas coleções africanas existentes em museus brasileiros, este dossiê tem o papel de colaborar para que mais um passo seja dado para o fortalecimento, no Brasil, do campo de reflexão sobre a cultura material da África, oferecendo aos leitores algumas das diferentes abordagens possíveis. Desde o início, imaginamos apresentar artigos de pesquisadores brasileiros e do exterior, de modo a permitir a confrontação de diferentes metodologias que vêm sendo aplicadas em estudos envolvendo o que se convencionou chamar de objetos, peças ou obras de arte da África.

O primeiro artigo, denominado "Tecido estrangeiro, hábitos locais: indumentária, insígnias reais e a arte da conversão no início da Era Moderna do reino do Congo" foi desenvolvido pela historiadora da arte e professora da Universidade de Chicago Cécile Fromont. Utilizando o conceito de "espaço de correlação", já explorado em seu livro The Art of Conversion: Christian Visual Culture in the Kingdom of Kongo, publicado em 2014, Fromont analisa as elaboradas transformações religiosas, políticas e materiais do reino do Congo, tendo como foco objetos como roupas, chapéus, espadas e imagens religiosas.

Já o artigo "'Clara como céu, escura como água do Luembe': trajetórias, usos e significados das contas de vidro entre as populações da África CentroOcidental (Lunda, 1884-1888)" é de autoria da historiadora e doutoranda Marcia Cristina Pacito Fonseca Almeida, no qual nos oferece um desdobramento de sua dissertação de mestrado. Aborda como a cultura material foi inserida na agenda científica da expedição portuguesa à Lunda, chefiada por Henrique de Carvalho 
entre 1884 e 1888, demonstrando o relevante papel que as contas vítreas, mais conhecidas como miçangas, desempenharam entre as sociedades centro-ocidentais africanas com as quais esse militar português teve contato.

De outra parte, Ana Cristina Pessoa Tavares e Maria do Rosário Antunes Rodrigues Martins, ambas do Museu de Ciência da Universidade de Coimbra, produziram o artigo "Singularidades museológicas de uma tábua com esculturas em diálogo: do alambamento ao casamento em Cabinda (Angola)", no qual analisam a rica narrativa da tábua de casamento recolhida pelos missionários do Espírito Santo, revelando como um único objeto pode ser de grande relevância para a compreensão dos códigos sociais e simbólicos compartilhados pelos cabinda. Lembro que essa mesma tábua de casamento foi exposta em São Paulo na mostra "Da Cartografia do poder aos itinerários do saber", realizada pelo Museu Afro Brasil em 2014.

artigo seguinte - "As esculturas cokwe como respostas às assimetrias civilizacionais" - é de minha autoria e se trata de um desdobramento de minha tese de doutorado. Enfoca uma das muitas iniciativas desenvolvidas pelo Museu do Dundo voltadas para a preservação da produção artística dos povos da Lunda. $\bigcirc$ receio da extinção de uma arte reminiscente do "tempo tribal" fez com que o Museu do Dundo mantivesse em seus domínios um grupo de escultores a fim de evitar que as transformações ocasionadas pela situação colonial influenciassem os trabalhos desses homens. No artigo, busco mostrar como os anseios fictícios do Museu em relação a esses artistas foram fundamentais para compreender as constantes tensões e dificuldades em enquadrar no seu espaço esses homens e suas produções.

Em seguida, apresentamos o artigo de Lia Dias Laranjeira, antropóloga e professora da Universidade da Integração Internacional da Lusofonia AfroBrasileira (UNILAB), denominado "Migração makonde, produção de esculturas e mercado de arte no Tanganyika: a questão do estilo Shetani (1950-60)", que tem como objetivo mostrar como a escultura makonde é um exemplo paradigmático de uma produção escultórica que marca a transformação dos tipos das peças e a relação dos escultores com os comerciantes dessa arte. Laranjeira explora ainda como o contexto de criação desse tipo de escultura no Tanganyka relaciona-se diretamente com a imigração em massa dos makonde de Moçambique para o norte do Rio Rovuma entre as décadas de 1950 e 1960, por conta da violência do regime colonial português.

Encerra o dossiê o artigo de Marta Heloisa Leuba Salum (Lisy Salum), professora do Museu de Arqueologia e Etnologia da Universidade de São Paulo. A antropóloga se destaca como a mais importante estudiosa da arte africana no país, tendo um papel primordial na construção desse campo. "Vistas sobre arte africana no Brasil: lampejos na pista da autoria oculta de objetos afro-brasileiros em museus" é o único artigo deste dossiê voltado para as produções afro-brasileiras e nele Lisy Salum expõe, conforme suas palavras, "uma experiência de interpretação de objetos em coleções atribuídos aos antigos candomblés, a partir da formação 
prévia de um corpus composto de esculturas publicadas por estudiosos da primeira metade do século XX". Trata-se da publicação de parte de um estudo mais amplo da autora focado em reconhecer as "marcas de um Brasil africano ou de uma África brasileira em objetos de coleção".

Esperamos que as diferentes propostas de análise da cultura material africana ou afro-brasileira apresentadas neste dossiê sejam um convite para que novos pesquisadores explorem esse rico universo temático, alargando um grupo ainda pequeno e colaborando para a consolidação desse importante campo de estudos no Brasil. 